\title{
Experimental study on the correlation between hill direct seeding rate and field seedling rate of typical rice varieties in cold areas
}

\author{
Han Tang ${ }^{1}$, Yeming Jiang ${ }^{1}$, Changsu Xu ${ }^{1}$, Wenqi Zhou ${ }^{1}$, Qi Wang ${ }^{1}$, Yijia Wang ${ }^{2 *}$ \\ (1. College of Engineering, Northeast Agricultural University, Harbin 150030, China; \\ 2. Department of Industrial and Manufacturing Systems Engineering, The University of Hong Kong, Pokfulam Road, Hong Kong, China)
}

\begin{abstract}
In order to examine the relationship between the seeding rate of a hill-direct-seeding machine and seedling rate in field, six rice varieties typical for cold areas were selected to conduct the indoor germination tests and field seedling experiment using a hill-direct-seeding machine. Indoor germination and field seedling tests were performed to study the correlation among the mechanical precision seeding process, machine seeding rate and field seedling rate. The results showed that the indoor germination rates were higher than $90 \%$. The series of spoons was adaptable to the hill-direct-seeding process. The number of seeds was 28-30, 18-20 and 8-10 grains/hill. The field seedling rates were higher than $85 \%$. The rice variety of Suijing-18 achieved the best field seedling rate, and the highest seeding rate was 18-20 grains/hill, while the average field seedling rate was $94.25 \%$. On this basis, the action law of the hill-direct-seeding machine and the main factors influencing the field seedling rate were analyzed. Mechanical vibration resulted in a higher average seeding rate of the middle seed metering device of the hill-direct-seeding machine than that of both ends. The force between the seed spoons and rice seeds mechanically damaged the seed buds, resulting in the actual field seedling rate being lower than the ideal indoor germination rate. The experimental results can provide a reference for the selection of typical direct seeding rice varieties, the improvement of key components of hill-direct-seeding machines, and the promotion of agronomic models.
\end{abstract}

Keywords: cold areas, rice, machine, hill-direct-seeding, seeding rate, seedling rate

DOI: $10.25165 /$ j.ijabe.20211405.6020

Citation: Tang H, Jiang Y M, Xu C S, Zhou W Q, Wang Q, Wang Y J. Experimental study on the correlation between hill direct seeding rate and field seedling rate of typical rice varieties in cold areas. Int J Agric \& Biol Eng, 2021; 14(5): 63-71.

\section{Introduction}

Rice is the main crop in China and plays an important role in ensuring the national food production security and strategic development ${ }^{[1]}$. With the development of modern agriculture, completely mechanized rice production, especially its high-quality and efficient planting technology, has become a reliable guarantee to promote the upgrading to a green and high-quality rice industry and change the mode of agricultural development ${ }^{[2]}$. Northern China is located at high latitudes, with a low temperature and a large temperature difference between day and night, thus forming the early-maturation single-cropping rice system suitable for cultivation in cold areas, and it is the largest commodity grain production base in China. The region's completely mechanized rice production approach has also been applied first in China, and the overall mechanization level reached $99.81 \%$ in $2019^{[3]}$. In contrast, the level of mechanized rice seeding in cold areas is only

\section{Received date: 2021-04-05 Accepted date: 2021-07-22}

Biographies: Han Tang, $\mathrm{PhD}$, Associate Professor, research interests: agricultural mechanization engineering and precision planting technology, Email: tanghan19910102@163.com; Yeming Jiang, Master candidate, research interests: agricultural mechanization engineering, Email: jiangyeming951120@ 163.com; Changsu $\mathbf{X u}, \mathrm{PhD}$ candidate, research interests: agricultural mechanization engineering, Email: xuchsu_123@163.com; Wenqi Zhou, PhD, Associate Professor, research interests: agricultural mechanization engineering and farm machinery, Email: zhouwenqi1989@163.com; Qi Wang, PhD, Lecturer, research interests: agricultural mechanization engineering and farm machinery, Email: wangqi_4034@163.com.

*Corresponding author: Yijia Wang, Postdoctoral, research interest: applications of machine learning and optimization theory in smart agriculture. Department of Industrial and Manufacturing Systems Engineering, The University of Hong Kong, Pokfulam Road, Hong Kong, China. Tel: +861662974902, Email: yijiawang@ connect.hku.hk.
$82.16 \%{ }^{[4]}$. A reasonable mechanized seeding technique is an important guarantee to improve crop yields and reduce labor requirements. According to the seeding mode, mechanized seeding methods can be divided into direct seeding and transplanting ${ }^{[5-7]}$. Precision hill direct seeding is a kind of direct seeding method. It is a simple seeding method that can accurately emplace rice seeds in hills according to the required plant spacing, row spacing and grain number under the premise of ensuring a certain seeding density. It eliminates the need for seedling raising, transporting and transplanting. It has the advantages of time and cost savings with an increased efficiency, and it has gradually become the main rice seeding method ${ }^{[8]}$.

Mechanical precision seed metering equipment mainly relies on mechanical force to separate seeds quantitatively and orderly and realizes the unrestricted and controlled seeding from the seed box to the seedbed. Its supporting mechanical seed metering device has the characteristics of a simple structure, convenient maintenance, low cost, etc. and is widely used ${ }^{[9,10]}$. In recent years, scholars have created various types of high-precision mechanical rice hill-direct-seeding devices, but there are still problems, such as strict requirements on the rice seed shape and size, and the quality of high-speed operation needs to be improved $^{[11-13]}$. The Northeast Agricultural University has designed an ejection ear spoon precision hill-direct-seeding device. The device adopts the methods of seed spoon filling, gravity and brush composite seed cleaning, flexible roller seed protection and ejection seeding, and a cold-area rice precision hill-direct-seeding machine has been developed ${ }^{[14]}$. In the process of application and popularization of this technique and machine, certain problems remain, such as the lack of typical direct seeding rice breeding, the suitable seeding rate for different varieties and the law of seedling 
formation in the field. These problems have not been investigated, and the performance of the supporting machine remains unstable. It is urgent to perform relevant research on the relationship between the machine seeding rate and the law of seedling formation of rice seeds to improve the application scope and operation quality of mechanization direct seeding.

In this context, to examine the law between the precision hill-direct-seeding rate and field seedling rate of rice seeds, the above designed precision hill-direct-seeding machine was selected as the research object, and a variety of single-cropping rice species typical for the cold area of northern China were selected as the test materials to conduct indoor germination and field seedling tests. The purpose of this study is to provide a reference for the selection of typical direct seeding rice varieties, the improvement of key components of the mechanized precision hill-direct-seeding method and the promotion of its agronomic model.

\section{Main structure and working principle of the precision hill-direct-seeding machine and seed metering device}

\subsection{Structure and working principle of the machine}

The precision hill-direct-seeding machine for cold-area rice is mainly composed of a precision seed metering system (ejection ear spoon precision hill-direct-seeding device, seed box, seed pipe and seed metering shaft), electric hill fertilization system (electrical drive exterior slot wheel fertilizer distributor, fertilizer pipe, fertilizer ditch opener, fertilizer box and fertilizer delivery pipe), combined auxiliary system (light frame, suspension frame, transmission box, bottom plate, height and horizontal profiling mechanisms, side mudguard and water storage ditch opener) and other components, and the overall structure is shown in Figure 1a. It is mainly driven by a ride-type high-speed transplanter chassis, with six symmetrically arranged rows in the middle. The suspension frame, bottom plate, side mudguard and water storage ditch opener are located on the light frame to realize the formation of flattened paddy wheel marks and to achieve ditching and ridging. The height and horizontal profiling mechanisms are hinged on the bottom plate to realize all-round profiling adaptable to complex and changeable working environments. The transmission box is installed in the middle of the bottom plate. The electric hill fertilization and precision seed metering systems are arranged on the front and back, respectively, of the light frame. Side deep fertilization and precision hill seeding are realized through the electric and chain drives, respectively. The test prototype is shown in Figure 1b. The water storage ditch opener at the bottom of the bottom plate opens several parallel water storage ditches simultaneously, and the section shape of a water storage ditch is trapezoidal, while the widths of the upper and lower sections are 100 and $80 \mathrm{~mm}$, respectively. The ditch depth is $40 \mathrm{~mm}$, and ridges are formed between adjacent water storage ditches. The fertilizer ditch opener is employed to open ditches in a stable manner, and the ditch width is $50 \mathrm{~mm}$, while the ditch depth can be adjusted. In addition, ditches are flattened by the bottom plate. The fertilizer distributor spacing is fixed, the row spacing of the distributors is $230 \mathrm{~mm}$, the fertilizer hill spacing ranges from 100$250 \mathrm{~mm}$, and the fertilization amount ranges from 1.8-6.0 g/hill. The seed metering device operates at fixed intervals, the seeding row spacing is $230 \mathrm{~mm}$, the spacing of the seeding hills ranges from 130-220 mm, and the seeding rate ranges from 6-20 grains/hill. The fertilizer distributor is $30 \mathrm{~mm}$ away from the rice seedling side and $50 \mathrm{~mm}$ below the ridge, which can be adapted to the single-cropping rice direct seeding mode in the cold area of northern China and facilitate the subsequent field management and harvest practices. The precision hill-direct-seeding machine for cold-area rice is a light and simple integrated device. The structure of the high-quality device is compact and simple. Seed metering and fertilizer application systems can be added according to the actual requirements to improve the operation universality and flexibility of the machine and improve its operation efficiency and quality.

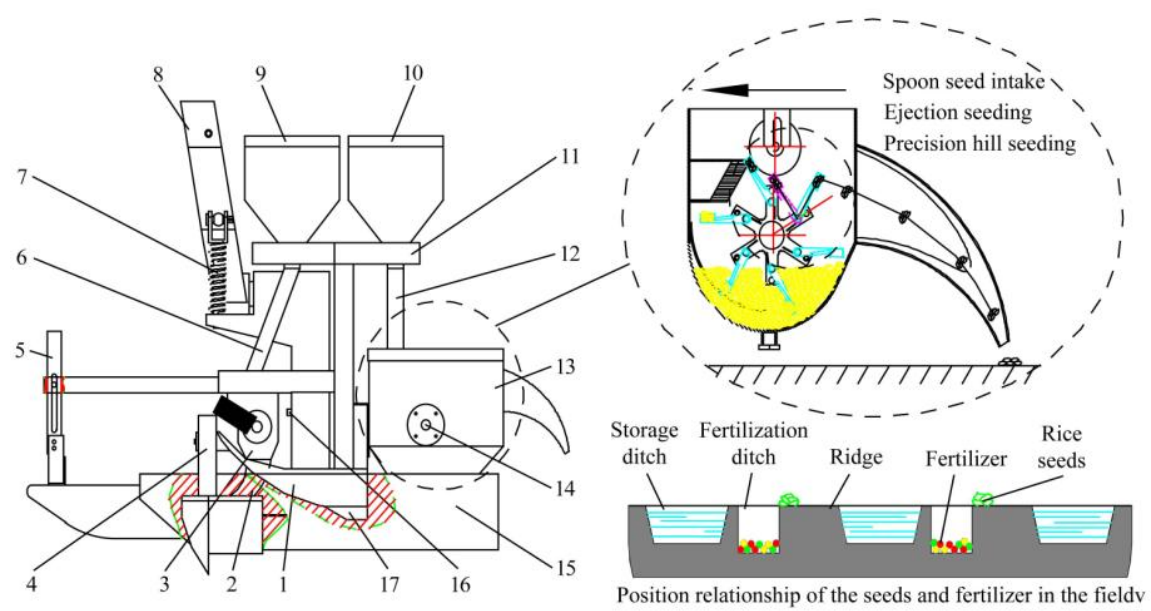

a. Overall structure of the machine and operation mode

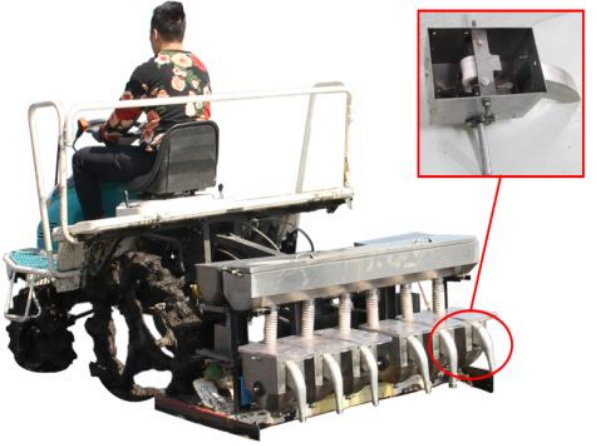

b. Prototype and seed metering device

1. Bottom plate 2. Fertilizer pipe 3. Electrical drive of the exterior slot wheel fertilizer distributor 4. Fertilizer ditch opener 5. Height profiling mechanism 6. Fertilizer pipe 7. Horizontal profiling mechanism 8. Three-point suspension 9. Fertilizer box 10. Seed box 11. Light frame 12. Fertilizer conveying pipe 13. Ejection ear spoon precision hill-direct-seeding device 14 . Seed metering shaft 15 . Side mudguard 16 . Transmission box 17 . Water storage ditch opener

Figure 1 Precision hill-direct-seeding machine for cold-area rice

In the precision hill-direct-seeding process, the machine is attached to the high-speed transplanter chassis, and the height and horizontal position are regulated by the profiling mechanism according to the terrain and field mud surface conditions to ensure smooth machine movement in the field. The water storage ditch opener opens a water storage ditch, and the fertilization ditch opener opens a fertilization ditch to establish a wet environment suitable for direct seeding and fertilization ${ }^{[15,16]}$. Power is transmitted from the output shaft, transmission box and chain drive to the seed metering shaft. A coupling connects the seed metering devices to ensure synchronous rotation. Spoon seed intake and ejection seeding are performed. The hill distance can be adjusted 
by varying the rotation speed of the power output shaft, and the seed amount can be tailored by changing the spoon of each type of seed metering device. Power is provided by a $12 \mathrm{~V} \mathrm{DC}$ storage battery on the chassis, which drives the motors of all fertilizer distributor rows and the exterior slot wheel fertilizer distributor to conduct side deep hill fertilization. The distance between the fertilization hills can be modified by adjusting the rotation speed of the fertilizer distributor. The fertilizer amount can be altered by changing the tongue opening of the fertilizer distributor to simultaneously perform precision hill direct seeding and side deep hill fertilization ${ }^{[17-19]}$. All components work together to complete the operations of ditching, fertilization, seeding and mud covering at the same time, which effectively improves the operation quality and stability ${ }^{[20]}$.

\subsection{Precision direct seeding metering device and series of model seed spoons}

As the core part of the direct seeding machine, the ejection ear spoon precision hill-direct-seeding device directly controls the seeding quality and efficiency. It is mainly composed of a seed spoon, torsion spring, rotating seed spoon plate, flexible seed protecting roller, seed cleaning brush, seed conveying pipe, seed box, seed metering shaft, pin shaft, stop bar, seed protecting roller seat and seed protecting roller mounting frame, as shown in Figure 2a. The operation process primarily includes seed filling, cleaning and protection and seeding. Seeds are filled in the seed filling area of the seed box under gravity. The seed metering shaft drives the seed spoon plate and seed spoon as a whole in a clockwise direction to mix the seeds thoroughly. Seeds fill the spoon under the action of gravity, thereby experiencing seed collision friction and seed spooning force. The seed cleaning brush processes a certain number of rice seeds in the spoon. When the seed spoon comes into contact with the flexible seed protecting roller, the seed spoon rotates anticlockwise around the pin shaft under the pressure of the seed protecting roller, disengages from the stop bar and changes the position of the single force arm of the torsion spring. As a result, a certain amount of elastic potential energy is accumulated, which produces an elastic force to rotate the seed spoon tightly against the flexible seed protecting roller. When the spoon is rotated to a certain angle relieving the pressing action of the seed protecting roller, the torsion spring releases the stored elastic potential energy, which drives the spoon to quickly rotate clockwise and contact the stop bar, thereby ejecting rice seeds into the seed conveying pipe along a parabolic trajectory. This completes the precise hill-direct-seeding operation ${ }^{[21]}$.

In this study, a series of spoon types was tested to adjust the seeding rate per hill, as shown in Figure 2b. By changing the main structural parameters of the spoon, including the depth $H$ and inner diameter $R$ of the spoon, a stable seeding rate ranging from 8-30 grains/hill (one spoon targets one hill) can be achieved. Combined with the agronomic requirements of rice direct seeding in cold areas and bench test results, large, medium and small seed spoons were selected as follow-up experimental research objects. Each group of 6 spoons was configured in one rotating seed spoon plate, and each machine contained 6 seed metering devices, namely, 36 spoons/set, for a total of 108 seed spoons. The depth $H$ and inner diameter $R$ of each type of seed spoon are $H=13 \mathrm{~mm}$ and $R=8.5 \mathrm{~mm}, H=9 \mathrm{~mm}$ and $R=8 \mathrm{~mm}$, and $H=7.5 \mathrm{~mm}$ and $R=6 \mathrm{~mm}$ corresponding to seeding rates of 8-10, 18-20 and 28-30 grains/hill, respectively. The spoons are shown in Figure 2c. Six seed spoons of the same set are uniformly arranged on the rotating seed spoon plate around the pin shaft, which can rotate with the seed metering shaft and drives the pin shaft to realize the seeding process, thus improving the consistency of the dispensed hill-direct-seeding quantity.

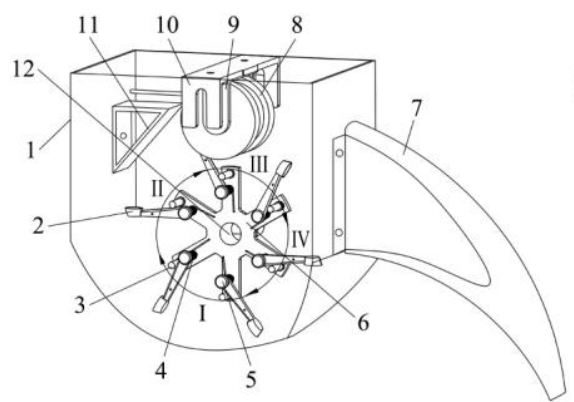

a. Precision hill-direct-seeding device

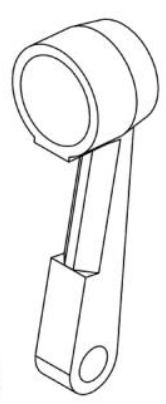

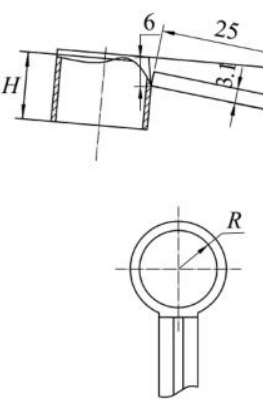

b. Seed spoon

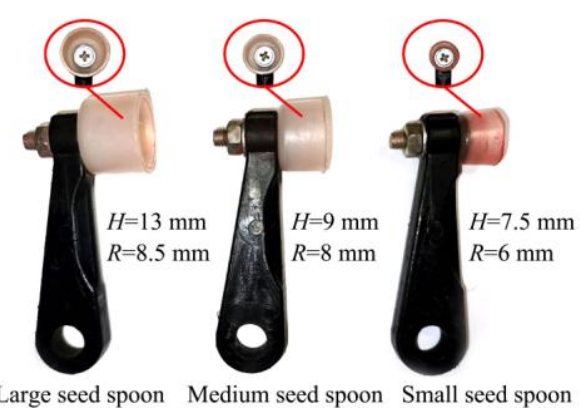

c. Series of model seed spoon

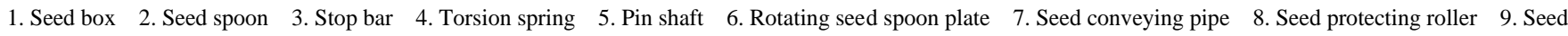
protecting roller seat 10 . Seed protecting roller mounting frame 11 . Seed cleaning brush 12 . Seed metering shaft

I-Seed filling area II-Seed cleaning area III-Seed protection area IV-Seeding area

Figure 2 Ejection ear spoon precision hill-direct-seeding device and series of seed spoon models

\section{Materials and methods}

\subsection{Test materials and conditions}

Through an investigation of the rice varieties widely planted in Heilongjiang Province in recent years, 6 typical cold-area rice varieties were selected as the research object. The selected 6 typical rice varieties were planted in the first, second, third and fourth accumulated temperature zones of Heilongjiang Province, representing the main varieties of high-quality and high-efficiency rice in Heilongjiang Province from 2018 to 2021. The selected varieties are representative and have considerable coverage in the study area. They include Suijing-18 (Japonica rice, long grain type, the 1000-grain weight is $26.5 \mathrm{~g}$ ), Longdao-18 (Japonica rice, long grain type, the 1000-grain weight is $27.6 \mathrm{~g}$ ), Dongnong-428
(Japonica rice, long grain type, the 1000-grain weight is $26.6 \mathrm{~g}$ ), Songjing-22 (Japonica rice, long grain type, the 1000-grain weight is $27.1 \mathrm{~g}$ ), Longqingdao-3 (Japonica rice, long grain type, the 1000 -grain weight is $27.2 \mathrm{~g}$ ) and Longjing-31 (Japonica rice, medium grain type, the 1000 -grain weight is $26.3 \mathrm{~g}$ ). Through manual grading and cleaning treatment, the shape of the tested rice seeds was uniform, and the rice seeds were complete and undamaged. The above varieties were provided by the Northeast Agricultural University, Heilongjiang Academy of Agricultural Sciences, and the Beidahuang Seed Industry Group Co., Ltd.

\subsection{Test method}

The main purpose of this study was to perform indoor germination and field seedling tests. In particular, an indoor environment suitable for rice seed germination was built, and the 
ideal germination rate of each rice seed variety was determined. On this basis, a field seedling test was conducted to examine the correlation between the mechanical precision seeding process, seeding rate and field seedling rate for each rice seed variety. By comparing the indoor germination rate and the field seedling rate of each rice seed variety, the most suitable conditions for the mechanical hill-direct-seeding process for each variety satisfying the field seedling requirements can be obtained, which provides an important reference for the improvement and optimization of the key components of the precision hill direct-seeding device.

\subsubsection{Indoor germination test}

To investigate the ideal germination conditions of rice seeds in typical cold areas in a suitable environment and comprehensively evaluate the influence of various factors on the field seedling rate of rice seeds, an indoor germination test was performed at the Northeast Agricultural University $\left(45.74^{\circ} \mathrm{N}, 126.72^{\circ} \mathrm{E}\right)$, Harbin city, Heilongjiang Province, from April 15 to April 30, 2019. The study was conducted with uniform, complete and undamaged rice

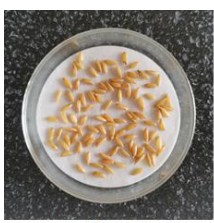

Suijing-18

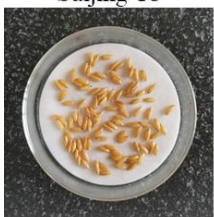

Songjing-22
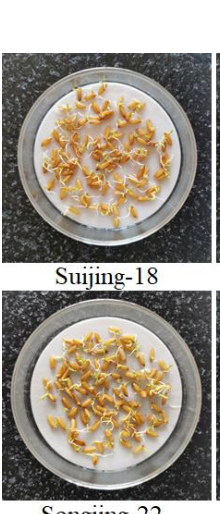

Songjing-22
Suijing-18

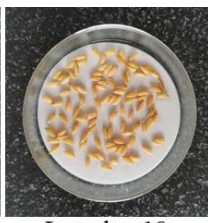

Longdao-18

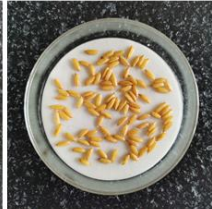

Longqingdao-3

a. Day 1

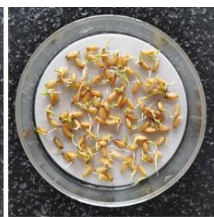

Longdao-18

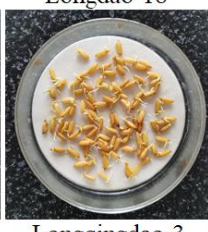

Longqingdao-3

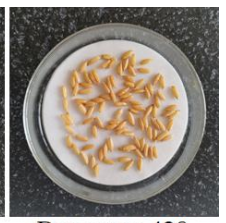

Dongnong-428

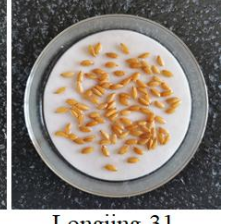

Longjing-31

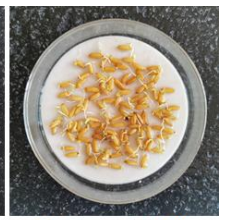

Dongnong-428

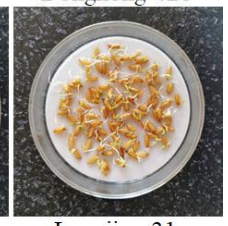

Longjing-31 c. Day 5

Figure 3

Germination process in the rice indoor germination test

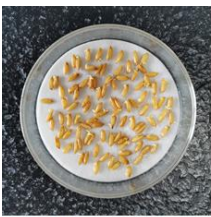

Suijing-18

Songjing-22

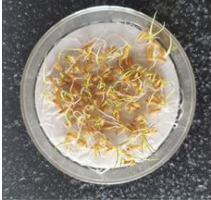

Suijing-18

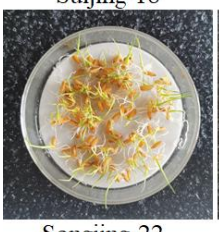

Songjing-22

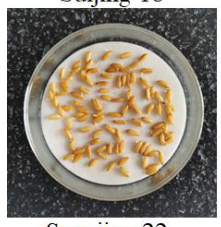

seeds. One hundred rice grains were randomly selected as one group, and each group was tested 5 times (500 grains/type). The selected rice seeds were soaked in water at room temperature at $20^{\circ} \mathrm{C}-25^{\circ} \mathrm{C}$ for $24 \mathrm{~h}$. Test paper was placed in a Petri dish, wetted with deionized water and affixed to the dish bottom to establish a suitable paper bed environment. After soaking, the rice seeds were removed and placed in paper bed-lined Petri dishes in groups. To reduce the interaction between the rice seeds in the germination and sprouting process, they were scattered as much as possible.

Each group of Petri dishes was placed in a constant-temperature incubator at $30^{\circ} \mathrm{C}$ for the germination test. Water was regularly added to the Petri dishes, and moist paper beds and a constant temperature were maintained to prevent the rice seeds from drying. The germination state in the Petri dish of each rice seed variety was recorded every day, and the germination rate of the rice seeds was calculated one week later. The germination process is shown in Figure 3. The germination rate of the rice seeds can be obtained through manual observation and calculation.

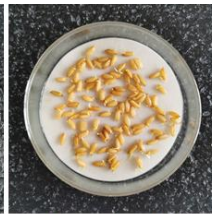

Longdao-18

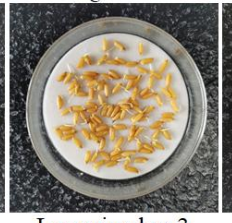

Longqingdao-3

b. Day 3

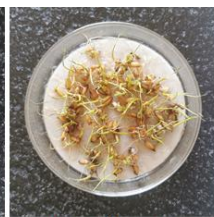

Longdao-18

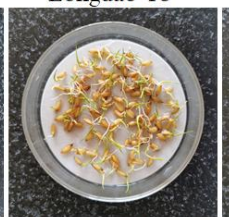

Longqingdao-3

d. Day 7

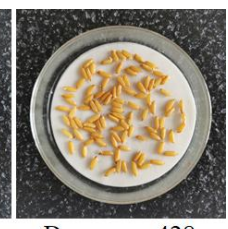

Dongnong-428

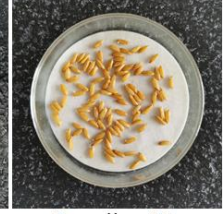

Longjing-31

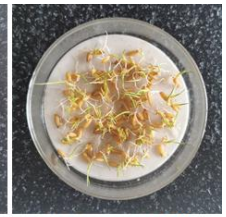

Dongnong-428

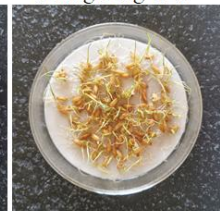

Longjing-31

\subsubsection{Field seedling test}

To accurately determine the most suitable seeding rate conditions for each rice seed variety to meet the field seedling requirements and analyze the mechanical function of the precision seeding device, the seeding rate and the field seedling rate, field seedling tests were performed at the Qing'an rice planting experimental base $\left(47.35^{\circ} \mathrm{N}, 128.35^{\circ} \mathrm{E}\right)$, Suihua city, from May 1 to May 30, 2019. The experimental area consisted of paddy fields in this cold region, and the soil type was clayey black loam. Before the test, a standard ridge was built by a corresponding ridge building machine, and rice straw was mixed in a $20-\mathrm{cm}$ soil layer by a designated straw returning machine to prevent the straw from floating when the surface is irrigated. Rotary cultivation with water and slurry was conducted with a rotary cultivator and slurry mixing grader, respectively, which ensured that the slurry in the test area was well mixed and that the field surface was homogeneous, soft and flat, and the maximum height difference of the slurry surface was less than $3 \mathrm{~cm}$. The test base is equipped with a bird net to cover the whole area to avoid the influence of birds on the rice seeds after seeding. The experimental machine was a precision rice hill-direct-seeding machine suitable for cold areas (with 6 rows). The driving machine was a Kubota 2ZGQ-6G2 (SPV-6CM) ride-type high-speed transplanter chassis (under a power of $14.4 \mathrm{~kW}$ ), which was equipped with conventional field test instruments.

In the field seedling test, all rice varieties were the same as the indoor germinated rice varieties. The rice seeds were screened via soaking in clear water. After soaking in clear water for $24 \mathrm{~h}$, the selected rice seeds were removed and further soaked indoors to accelerate germination until they germinated and sprouted. When 
$80 \%$ of the rice seeds had germinated and sprouted and the length of the seed buds was smaller than $2 \mathrm{~mm}$, they were ready for use. The rice seeds were placed in a $5^{\circ} \mathrm{C}-10^{\circ} \mathrm{C}$ environment to stunt their growth, thus ensuring that the buds were short and hard and not easily damaged through mechanical action, which would block the seed metering system. The average moisture content of the rice seeds in the field test was $22.3 \%$ (wet basis). According to relevant test methods of national standards "NY/T987-2006 operating quality grain film-covering hill-drop drill", "NY/T1143-2006 technical specification of quality evaluation for drills" and "GB/T25418-2010 rice direct seeder with soil cover" ${ }^{\text {[22-24] }}$, the test area was divided into a starting area, test area and stop area. The starting and stopping areas were $10 \mathrm{~m}$ long. The field tests were conducted on the abovementioned 6 kinds of rice seeds with a precision rice hill-direct-seeding machine suitable for cold areas (6 rows).

Combined with theoretical analysis and performance test research of precision hill-direct-seeding metering devices ${ }^{[25]}$, the test was performed under certain conditions to ensure good operation effects. The forward speed of the machine was $1.3 \mathrm{~km} / \mathrm{h}$, and the rotation speed of the seed metering device was $30 \mathrm{r} / \mathrm{min}$. By changing the ear spoon series, the seeding rate (8-10, 18-20 and 28-30 grains/hill) of the machine could be adjusted. The working state of the seed metering device was adjusted through a field static pre-test to ensure that the same type of ear spoon could achieve the same seeding amount under stable working conditions, and manual detection was carried out. Six groups of repeated tests were performed at the same time in one operation (six rows were seeded with the same rice seeds). A comparison test of the six groups of rice varieties was completed through the six field direct seeding tests. The field test status is shown in Figure 4.

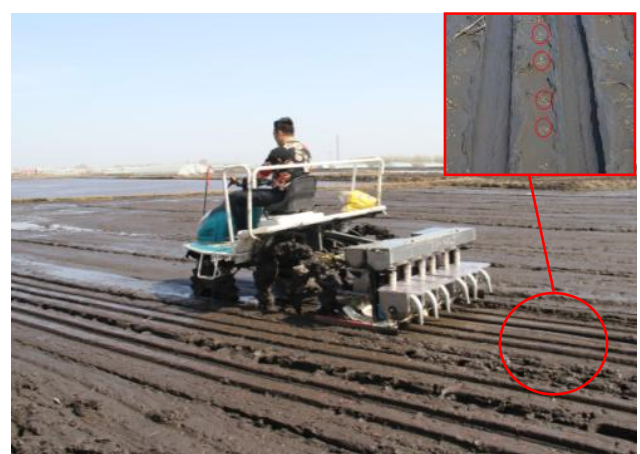

a. Working process of the precision hill-direct-seeding device

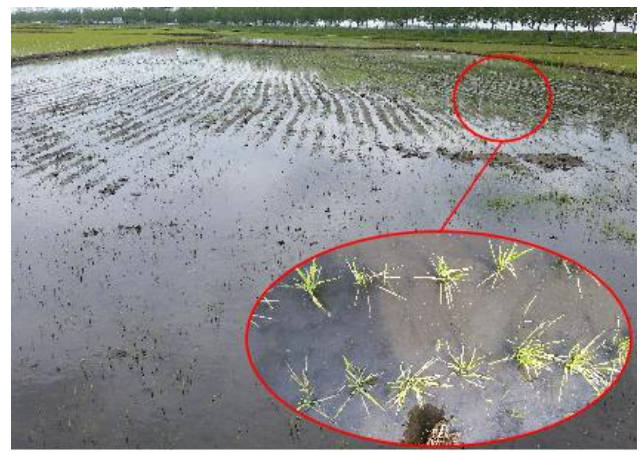

b. Germination of the rice seeds and seedlings in the field Figure 4 Field test status

\subsection{Data acquisition and processing}

Six groups of repeated tests were carried out for each rice variety in one operation. Each row of the seed metering device was numbered from 1-6 from left to right, and the seeding precision of each row was recorded. A total of 250 hills were randomly selected from each row, for a total of 1500 hills for each rice variety, and another $2 \mathrm{~m}^{2}$ was selected for each rice variety to reduce the test error. In the process of direct seeding, side deep fertilization was synchronously performed by the mechanical fertilization system. After seeding, reasonable water slurry management was executed to ensure that the rice seeds remained rooted, tilled and submerged in shallow water. Because directly seeded rice seeds are sensitive to external factors such as the moisture content and temperature, shallow-water layer irrigation was maintained every day to ensure that the surface soil in the field was hard and that irrigation did not lead to the dispersal of hill rice seeds, which effectively reduced the damage due to low temperatures, pests and rats, ensured the best water and aeration conditions for the direct seeding of rice seeds, and minimized the impact of the external environment on the rice seedling rate ${ }^{[26,27]}$. After $15 \mathrm{~d}$, the field seedlings of each rice variety were manually measured. According to the agronomic requirements, seedlings were assumed to have formed when tillering began. The data were processed with EXCEL software, and the indoor germination and field seedling rates were compared to evaluate the influence of the seeding and field seedling rates for each rice variety.

\section{Results and analysis}

\subsection{Results and analysis of the indoor germination test}

In this study, the germination rate of each rice seed variety under suitable growth conditions was measured. This index represented the ideal seedling rate of the rice seeds, and the results were compared to the subsequent field seedling test results to analyze the mechanical effect as a function of the spoon series and rice variety and the effect of the hill-direct-seeding machine seeding rate on the field seedlings.

Table 1 indicates that the indoor germination rate of all rice varieties is higher than $90 \%$, among which the indoor germination rates of Suijing-18, Longdao-18, Dongnong-428, Songjing-22, Longqingdao-3 and Longjing-31 were 95.8\%, 93.6\%, 92.8\%, $92.2 \%, 91.6 \%$ and $91.2 \%$, respectively. The germination rate stability of Suijing-18 was the highest, and its coefficient of variation was $0.8 \%$, while the germination rate stability of Songjing-18 was the lowest, with a coefficient of variation of $1.70 \%$. In this study, the effect of external factors on the rice seeds could be ignored, and the indoor germination rate of each rice seed variety was regarded as the ideal field seedling rate. In the field test, it was important to determine the conditions under which the field seedling rate would be the closest to the indoor germination rate by using the hill-direct-seeding machine.

Table 1 Indoor germination rate of the rice seeds (\%)

\begin{tabular}{lccccccc}
\hline \multirow{2}{*}{ Rice varieties } & \multicolumn{9}{c}{ Germination rate } & Average & $\begin{array}{c}\text { Variation } \\
\text { coefficient }\end{array}$ \\
\cline { 2 - 5 } & 1 & 2 & 3 & 4 & 5 & & 0.80 \\
\hline Suijing-18 & 97 & 95 & 96 & 96 & 95 & 95.80 & 0.90 \\
Longdao-18 & 94 & 93 & 95 & 93 & 93 & 93.60 & 1.00 \\
Dongnong-428 & 93 & 92 & 94 & 93 & 92 & 92.80 & 1.70 \\
Songjing-22 & 91 & 90 & 93 & 93 & 94 & 92.20 & 1.20 \\
Longqingdao-3 & 92 & 90 & 92 & 93 & 91 & 91.60 & 1.40 \\
Longjing-31 & 92 & 90 & 91 & 90 & 93 & 91.20 & \\
\hline
\end{tabular}

Note: 1-5 are the number of test groups in the table.

\subsection{Results and analysis of the field seedling test}

The field seedling experiment was executed under controlled machine working conditions, and repeated hill-direct-seeding tests were performed for the same rice seed varieties in 6 rows 
simultaneously, and the seeding rate of each rice seed variety was adjusted (8-10, 18-20 and 28-30 grains/hill) via the use of the three ejection ear spoon types. After the precision hill-direct-seeding operation, the accuracy of the dispensed seeding quantity of the 6-row seed metering device for each rice seed variety was determined, as summarized in Table 2.

Table 2 reveals that the adaptability of the various seed spoons to the rice seed hill-direct-seeding process is good. The actual average seeding rates of the small seed spoons were 8.55, 11.39, $8.83,11.08,7.60$ and 9.44 grains/hill for Suijing-18, Longdao-18, Dongnong-428, Songjing-22, Longqingdao-3 and Longjing-31, respectively. The actual average seeding rates obtained with the medium seed spoons were 18.93, 20.73, 17.48, 21.91, 17.51 and 18.52 grains/hill for Suijing-18, Longdao-18, Dongnong-428, Songjing-22, Longqingdao-3 and Longjing-31, respectively. The actual average seeding rates with the large seed spoons were 28.53 , 31.04, 27.21, 31.67, 27.82 and 27.70 grains/hill for Suijing-18, Longdao-18, Dongnong-428, Songjing-22, Longqingdao-3 and Longjing-31, respectively. The stability of each spoon type was 28-30, 18-20 and 8-10 grains/hill, and the coefficient of variation increased with increasing seeding rate.

Table 2 Accuracy of the seeding rate of each row of the seed metering device

\begin{tabular}{|c|c|c|c|c|c|c|c|c|c|}
\hline \multirow{2}{*}{ Rice varieties } & \multirow{2}{*}{$\begin{array}{l}\text { Standard seeding } \\
\text { rate/grains per hill }\end{array}$} & \multicolumn{6}{|c|}{ Actual seeding rate of each row/grains per hill } & \multirow{2}{*}{$\begin{array}{c}\text { Average } \\
\text { /grains per hill }\end{array}$} & \multirow{2}{*}{$\begin{array}{c}\text { Variation } \\
\text { coefficient } / \%\end{array}$} \\
\hline & & 1 & 2 & 3 & 4 & 5 & 6 & & \\
\hline \multirow{3}{*}{ Suijing-18 } & $8-10$ & 7.11 & 8.32 & 10.43 & 9.87 & 8.78 & 6.76 & 8.55 & 0.17 \\
\hline & $18-20$ & 17.20 & 18.12 & 20.34 & 20.98 & 19.89 & 17.07 & 18.93 & 0.09 \\
\hline & $28-30$ & 26.9 & 28.05 & 29.99 & 30.34 & 28.86 & 27.05 & 28.53 & 0.05 \\
\hline \multirow{3}{*}{ Longdao-18 } & $8-10$ & 9.97 & 10.67 & 13.71 & 12.62 & 11.29 & 10.08 & 11.39 & 0.13 \\
\hline & $18-20$ & 18.76 & 20.11 & 22.62 & 23.55 & 19.99 & 19.34 & 20.73 & 0.09 \\
\hline & $28-30$ & 28.71 & 30.45 & 33.67 & 32.65 & 30.77 & 29.98 & 31.04 & 0.06 \\
\hline \multirow{3}{*}{ Dongnong-428 } & $8-10$ & 6.89 & 8.87 & 9.99 & 10.67 & 8.98 & 7.56 & 8.83 & 0.16 \\
\hline & $18-20$ & 15.89 & 17.23 & 19.73 & 18.96 & 16.96 & 16.09 & 17.48 & 0.09 \\
\hline & $28-30$ & 26.01 & 27.32 & 28.76 & 28.94 & 27.18 & 25.06 & 27.21 & 0.06 \\
\hline \multirow{2}{*}{ Songjing-22 } & $8-10$ & 9.90 & 10.02 & 12.88 & 13.34 & 11.76 & 8.57 & 11.08 & 0.17 \\
\hline & $28-30$ & 28.97 & 31.32 & 33.19 & 34.99 & 32.47 & 29.09 & 31.67 & 0.07 \\
\hline \multirow{3}{*}{ Longqingdao-3 } & $8-10$ & 5.92 & 7.13 & 9.22 & 8.99 & 7.45 & 6.89 & 7.60 & 0.17 \\
\hline & $18-20$ & 16.12 & 18.09 & 18.77 & 19.23 & 17.85 & 15.01 & 17.51 & 0.09 \\
\hline & $28-30$ & 26.91 & 27.98 & 28.92 & 30.01 & 28.28 & 24.81 & 27.82 & 0.06 \\
\hline \multirow{3}{*}{ Longjing-31 } & $8-10$ & 7.07 & 9.76 & 10.03 & 11.21 & 9.93 & 8.61 & 9.44 & 0.15 \\
\hline & $18-20$ & 16.32 & 17.77 & 20.49 & 20.64 & 18.90 & 17.02 & 18.52 & 0.10 \\
\hline & $28-30$ & 25.71 & 28.76 & 28.87 & 29.04 & 27.03 & 26.81 & 27.70 & 0.05 \\
\hline
\end{tabular}

Note: 1-6 are the number of seed metering devices in the table, i.e., the seeding rate of each row in one operation

To further analyze the influencing factors of the seeding rate accuracy and adaptability of the rice varieties in the process of hill direct seeding, the data in Table 1 were processed, as shown in Figure 5.

Figure 5a reveals that the average seeding rate of the middle seed metering device (row nos. 3 and 4 ) of the direct seeder for each rice seed variety was higher than that of the row at either end of the seed metering device (row nos. 1 and 6), and the distribution was basically symmetrical. The main reason is that the stability of the middle part of the machine suspension is the greatest, and the vibration of the cantilever at both ends of the frame is notable, especially in the seeding stage by using ear spoons. The rice seeds easily slid and fell, which affected the seeding stability of the seed metering device. In addition, adjusting the seed cleaning brush and seed protection roller impacts scooping, seed cleaning and seed protection. If the angle and distance between the two parts are too small, the compression deformation of the seed cleaning brush will be accelerated after contacting the rice seeds, the seed cleaning time will be reduced, and the maximum seed cleaning force on the rice seeds will be increased, resulting in a greater seed cleaning effect and a reduced seeding rate on one hill. If the angle and distance between the two parts are too large, the seeds carried by the seed spoon and the seed protection roller contact and rotate synchronously after seed cleaning, and there is no relative movement between the two parts. Problems related to abrasion, seed clamping and seed injury caused by the relative movement between the seed spoon and the seed protection roller are avoided, and the seeding quality and rate are ensured. At the same time, the seeding rate on one hill is larger. Moreover, the flow of water and slurry in the two adjacent rows during machine operation readily caused the seeds to be scattered, which also increased the difficulty of detecting the number of rice grains in the hills, but the overall seeding rate satisfied the design requirements of the spoons.

As shown in Figure 5b, the seed metering device attained the best adaptability to Suijing-18 in terms of the seeding rate, and the seeding rate with each seed spoon type remained within the required range. The seeding rate of Longdao-18 and Songjing-22 with the seed metering device is high for all seed spoon types, namely, slightly higher than the required seeding rate range, and the seeding rate of Dongnong-428, Longqingdao-3 and Longjing-31 with the seed metering device is low for all seed spoon types, namely, slightly lower than the required seeding rate range. The main reason is that there are differences in the shape and size of the different rice varieties. According to the difference in the triaxial arithmetic mean particle size and sphericity, the varieties were divided into long grain (triaxial arithmetic mean particle size larger than $4.3 \mathrm{~mm}$ and ratio of length to width greater than 2), ellipsoid grain (triaxial arithmetic mean particle size less than $4.3 \mathrm{~mm}$ and ratio of length to width of 1.5-2.0) and spheroid 
grain (triaxial arithmetic mean particle size less than $4.3 \mathrm{~mm}$ and ratio of length to width less than 1.5). When the spoon of the metering device rotates to fill the seeds under stable working conditions, the orientation of rice seeds in the spoon may be flat, standing up or lying on their side. Theoretical analysis and pre-test results show that the probability of rice seeds being stably scooped into the spoon is proportional to the cross-sectional area of lying flat, standing or lying on their side, and the filling probability of lying flat and lying on their side accounts for more than $80 \%{ }^{[28]}$. Therefore, the seed size of different grain types of rice varieties has an important impact on the seeding rate. The seeding rate is relatively high for rice with a smaller size and more uniform shape (ellipsoid and spheroid grain) and relatively low for rice with a larger size and more irregular shape (long grain). In addition, the uneven rice seed surface will also affect the interaction between the rice seeds in each group, resulting in a random influence on the seeding rate in the seeding process.

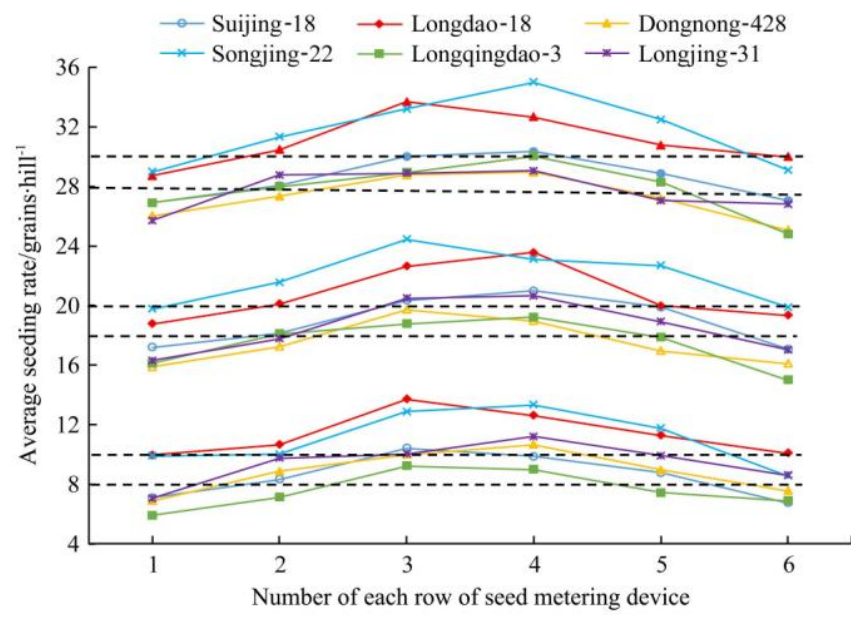

a. Uniformity of the seeding rate for each row of the seed metering device

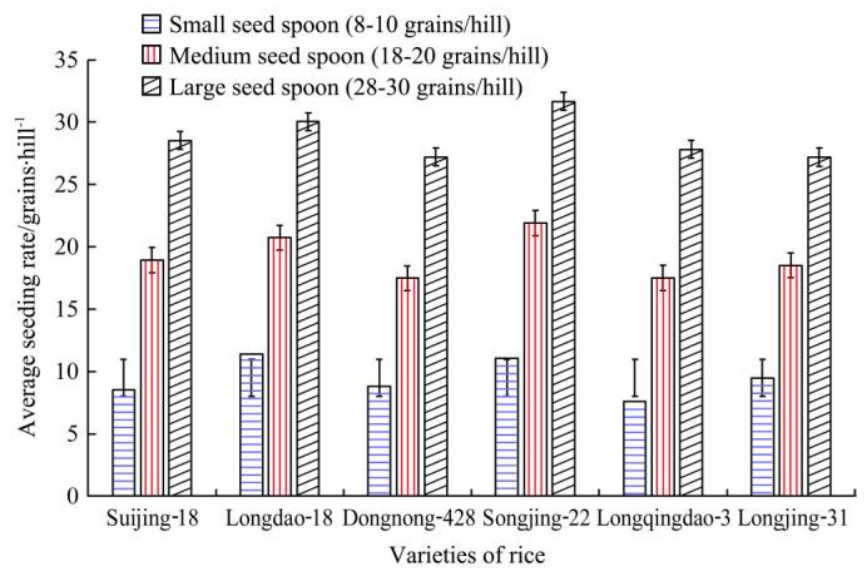

b. Adaptability of the seeding rate for the different varieties

Figure 5 Accuracy of field seeding

On this basis, reasonable water and slurry management was executed for the direct seeding process of rice seeds in the test area to minimize the impact of external factors on seedling formation. After $15 \mathrm{~d}$, statistics were obtained for the field seedling rate of each rice seed variety regarding the seeding rate for all seed spoon types. The actual average field seedling rates are listed in Table 3. Table 3 indicates that the highest field seedling rate of Suijing-18 was 18-20 grains/hill, with an average seedling rate of $94.25 \%$, and the highest field seedling rate of Longdao-18 was 28-30 grains/hill, with an average seedling rate of $91.23 \%$, while the highest field seedling rate of Dongnong-428 was 8-10 grains/hill, with an average seedling rate of $90.01 \%$. The highest field seedling rate of Songjing-22 was 18-20 grains/hill, with an average seedling rate of $91.03 \%$, and the highest field seedling rate of Longqingdao-3 was 28-30 grains/hill, with an average seedling rate of $90.97 \%$. The data in Table 3 were processed to further analyze the influence of various factors on the seedling rate of the rice seeds, as shown in Figure 6.

Table 3 Field seedling rate of the rice varieties

\begin{tabular}{|c|c|c|c|c|c|}
\hline \multirow[b]{2}{*}{ Rice variety } & \multicolumn{3}{|c|}{ Actual average seedling rate $/ \%$} & \multirow{2}{*}{$\begin{array}{c}\text { Ideal } \\
\text { seedling } \\
\text { rate } \%\end{array}$} & \multirow{2}{*}{$\begin{array}{c}\text { Good seeding } \\
\text { rate/ } \\
\text { grains } \cdot \text { hill }\end{array}$} \\
\hline & $\begin{array}{c}8-10 \\
\text { grains }^{2} \text { hill }\end{array}$ & $\begin{array}{c}18-20 \\
\text { grains }^{\prime} \text { hill }\end{array}$ & $\begin{array}{c}28-30 \\
\text { grains }^{2} \text { hill }^{-1}\end{array}$ & & \\
\hline Suijing-18 & 93.11 & 94.25 & 92.08 & 95.80 & $18-20$ \\
\hline Longdao-18 & 89.24 & 88.98 & 91.23 & 93.60 & $28-30$ \\
\hline Dongnong-428 & 90.01 & 87.19 & 85.13 & 92.80 & $8-10$ \\
\hline Songjing-22 & 89.32 & 91.03 & 87.91 & 92.20 & $18-20$ \\
\hline Longqingdao-3 & 86.52 & 91.34 & 85.68 & 91.60 & $18-20$ \\
\hline Longjing-31 & 90.01 & 88.75 & 90.97 & 91.20 & $28-30$ \\
\hline
\end{tabular}

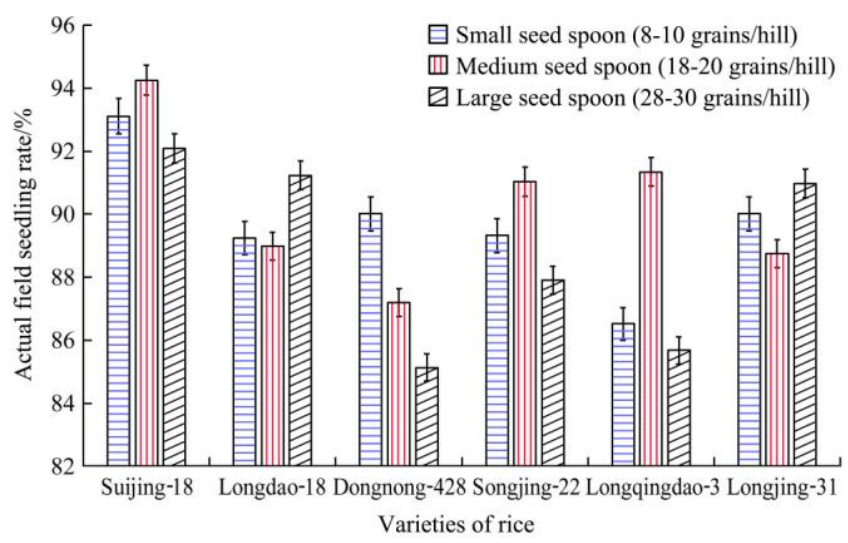

Figure 6 Field seedling rate of the rice varieties

Figure 6 shows that the field seedling rate of Suijing-18 is high for each seed spoon type, i.e., it is more suitable for precision hill direct seeding than the other rice varieties. The actual average seedling rate of the six rice varieties in the field is lower than the indoor ideal seedling rate but higher than $85 \%$, which satisfies the requirements of direct seeding and rice breeding. The main reason is that the seed spoons of the seed metering device stir the seeds of the various groups mechanically, and the resulting friction, collision and contact between the mechanical components of the seed metering device and the seeds are relatively complex. In the process of seed cleaning and seeding, the seeds in the spoons were rubbed by the rigid brush and round roller, which may cause mechanical damage to the short seed buds. All varieties of rice seeds are composed of basic seedlings and seed buds. The mechanical properties of the two parts are also different. In the filling process of the seed metering device, the seed buds will also be affected by the pressure and impact of the surrounding rice seeds and the backlog of the seed box. If the force is too large, the basic seedlings and seed buds of the rice seeds will endure mechanical damage, especially the seed buds, which are easy to break, thus affecting the rice field seedling rate. To further verify the effect of different degrees of mechanical damage on the field seedling rate. 100 seeds of different varieties were randomly selected, and the buds were cut according to different lengths. The cut length difference of each group was $0.5 \mathrm{~mm}$, that is, $0.5-2.0 \mathrm{~mm}$. The cut-off buds were directly seeded in precision hills to observe and analyze their continuous growth ability. Each variety was treated 3 times. The results showed that the continuous seedling rate was still more than $90 \%$ after reducing the 
length of the seed buds, which had a certain effect on the continuous germination and growth ability, but not significant. Moreover, the cold field direct seeding environment was more complex than the indoor environment. As the seeding rate among different rice varieties increases, the total number of basic seedlings in the field will increase. The internal competition among rice seedlings, which is not conducive to the growth of rice, and excessive planting density are not conducive to the ventilation and lighting of rice seedlings. Although the field management at the later stages is reasonable, many natural conditions, such as temperature, humidity and pest occurrence, cannot be completely controlled. The above mechanical effects and external uncontrollable factors directly lead to the actual field germination rate of each rice variety being lower than the ideal indoor germination rate.

\subsection{Discussion}

In the precision hill-direct-seeding process of rice in cold areas, too few grains in a single hill can easily cause the growth rate of the rice seeds in the field to be very low due to the influence of low temperatures, pests and rats, while too many grains in a single hill can easily cause excessive seedling formation of the rice seeds for each group, and the internal competition between adjacent rice seedlings affects the subsequent growth and is not conducive to suitable light and ventilation conditions ${ }^{[29]}$. Therefore, it is of great significance to conduct research on the correlation between the seeding rate and field seedling rate for each rice variety. The best stable seeding rate can be obtained by carefully selecting the seed spoon type before seeding. In addition, this has a certain reference value for the improvement and optimization of the key components of similar seed metering devices ${ }^{[30]}$.

To ensure that the field seedling rate is higher than $85 \%$, according to the growth characteristics of rice in cold areas, it is necessary to ensure the indoor germination rate and field seeding rate of each rice seed from the perspective of agronomic planting and further improve and optimize the structure of the seed metering device, especially the seed spoon, seed cleaning brush, seed guide roller and box shape. If the seeding rate of the precision hill-direct-seeding device is too small and the precision is low, when the rice seedling rate is low, there will be a higher rate of empty seedlings. If the seeding rate of the precision hill-direct-seeding device is too large, it will not only waste rice seeds but also affect the overall field seeding quality. This is mainly due to the large tillering amount of rice seeds in cold regions. Increasing the seeding rate will lead to an excessive number of seedlings in the field, increased internal competition among seedlings, and excessive planting density; these conditions are not conducive to field ventilation and lighting. However, rice in cold areas has a strong adaptive ability. In the case of empty seeding, tillering the rice seeds around the empty hill will be better than that of rice seeds in others; thus, the emergence of a lower empty seedling rate will not have a great impact on the final yield. This analysis also matches prior agricultural research ${ }^{[31]}$.

To effectively improve the field seedling rate of the various rice varieties, a seed selection machine can be adopted for intelligent screening during the actual hill-direct-seeding process ${ }^{[32]}$, and a certain amount of chemicals can be added during seed soaking to improve the germination rate and adaptability of the seed metering device. The field seedling rate is only the primary stage of rice seed growth, and the rice yield and quality are still affected by the subsequent weeding, fertilization and spraying ${ }^{[33-35]}$.
In a future study, under the condition of mechanical hill-direct-seeding operation, the influence of the seeding rate, seedling formation, field management and yield of typical rice varieties will be performed, and the most suitable standards and regulations related to mechanical hill-direct-seeding operation for the integration of agricultural machinery and agronomy will be investigated. This study provides a reference for the cultivation of typical direct seeding rice varieties, the improvement and optimization of key components of precision hill-direct-seeding machines and the promotion of agronomic models.

\section{Conclusions}

In this study, the results of the indoor germination test showed that the indoor germination rate of all rice varieties was higher than $90 \%$. The results of the field seedling test revealed that the adaptability of the series of spoons was good for the direct seeding of all rice varieties, and the seeding rate stability was 28-30, 18-20 and 8-10 grains/hill with increasing spoon size. The field seedling rate of all varieties was higher than $85 \%$, which met the requirements of direct seeding and rice breeding, among which Suijing-18 attained the highest seedling rate in the field, at 1820 grains/hill, and the average seedling rate was $94.25 \%$. Further analysis was made on the mechanical action rule of precision hill direct seeding and the main factors influencing the field seedling rate namely, the average seeding rate of the middle rows of the seed metering device was higher than that of the two end rows of the seed metering device due to mechanical vibration. The seeding rate of each variety was different due to the different shape and size of the rice seeds and the mechanical damage of the seed buds caused by friction, collision and contact between the seed spoons and seeds. The above reasons resulted in the actual field germination rate of the rice varieties being lower than the ideal indoor germination rate.

\section{Acknowledgements}

This research was financially supported by the National Natural Science Foundation of China (Grant No. 31901414), the Natural Science Foundation of Heilongjiang Province of China for Excellent Youth Scholars (YQ2021E003) and the Youth Talent Support Program of Northeast Agricultural University of China (Grant No. 19QC41).

\section{[References]}

[1] Zhang H C, Gong J L. Research status and development discussion on high-yielding agronomy of mechanized planting rice in China. Scientia agricultural Sinica, 2014; 47(7): 1273-1289. (in Chinese)

[2] Luo X W, Liao J, Hu L, Zang Y, Zhou Z Y. Improving agricultural mechanization level to promote agricultural sustainable development. Transactions of the CSAE, 2016; 32(1): 1-11. (in Chinese)

[3] Sui B, Dong S S, Meng H B, Wang J R, Shen Y J, Ding J T, et al Innovation in agricultural engineering and technology to accelerate green development of agriculture. Transactions of the CSAE, 2020; 36(2): 1-6. (in Chinese)

[4] Zhu M, Sui B, Qi F, Yang Z. Innovation of agricultural engineering management in pursuing rural revitalization strategy in China. Transactions of the CSAE, 2019; 35(2): 1-9. (in Chinese)

[5] Wang Y, Zhang Z L, Zhang Y S, Cui H G. Research and progress of rice direct sowing at home and abroad. Journal of Agricultural Mechanization Research, 2007; 29(1): 48-50. (in Chinese)

[6] Xu Y Y, Liu Y T, Wang J H, Wang Y X, Gao P, Yang H Y, et al. Research status and development prospect of rice direct seeding in dry land Heilongjiang Agricultural Sciences, 2018; 6: 150-152. (in Chinese)

[7] Asibi A E, Chai Q, Coulter J A. Rice Blast: A disease with implications for global food security. Agronomy 2019; 9(8): 451 
[8] Farooq M, Siddique K, Rehman H, Aziz H, Lee D, Wahid A. Rice direct seeding: experiences, challenges and opportunities. Soil \& Tillage Research, 2011; 111(2): 87-98.

[9] Zhang M H, Wang Z M, Luo X W, Zang Y, Yang W W, Xing H, et al. Review of precision rice hill-drop drilling technology and machine for paddy. Int J Agri \& Biol Eng, 2018; 11(3): 1-11.

[10] Shi S, Liu H, Wei G J, Zhou J L, Jian S C, Zhang R F. Optimization and experiment of pneumatic seed metering device with guided assistant filling based on EDEM-CFD. Transactions of the CSAM, 2020; 51(5): 54-66. (in Chinese)

[11] Dai Y Z, Luo X W, Zhang M H, Lan F, Zhou Y, Wang Z M. Design and experiments of the key components for centralized pneumatic rice dry direct seeding machine. Transactions of the CSAE, 2020; 36(10): 1-8. (in Chinese)

[12] Tian L Q, Wang J W, Tang H, Li S W, Zhou W Q, Shen H G. Design and performance experiment of helix Grooved rice seeding device. Transactions of the CSAM, 2016; 47(5): 46-52. (in Chinese)

[13] Wang J W, Zhang Z, Wang F, Jiang Y M, Zhou W Q. Design and experiment of monitoring system for rice hill-direct-seeding based on piezoelectric impact method. Transactions of the CSAM, 2019; 50(6): 74-84, 99. (in Chinese)

[14] Wang J W, Tang H, Sun X B, Tian L Q, Wang F. Mechanism analysis and performance optimization of rebound dipper rice precision hill-drop drilling seed metering device. International Agricultural Engineering Journal, 2018; 27(24): 197-212.

[15] Zhang M H, Luo X W, Wang Z M, Wang B L, Xue Z L. Optimization design and experiment of profiling and slide board mechanism of precision rice hill-drop drilling machine. Transactions of the CSAE, 2017; 33(6): 18-26. (in Chinese)

[16] Li Y H, Yang L, Zhang D X, Cui T, Zhang K L, Xie C J, et al. Analysis and test of linear seeding process of maize high speed precision metering device with air suction. Transactions of the CSAE, 2020; 36(9): 26-35. (in Chinese)

[17] Xu L, Li X X, Wang X Y, Xiong D L, Wang F. Comparing the grain yields of direct-seeded and transplanted rice: a meta-analysis. Agronomy 2019; 9(11): 767.

[18] Kumar V, Ladha J. Direct seeding of rice: recent developments and future research needs. Advances in Agronomy, 2011; 111: 297-413.

[19] Tang H, Wang J W, Xu C S, Zhou W Q, Wang J F, Wang X. Research progress analysis on key technology of chemical fertilizer reduction and efficiency increase. Transactions of the CSAM, 2019; 50(4): 1-19. (in Chinese)

[20] Xing H, Zang Y, Wang Z M, Luo X W, Pei J, He S Y, et al. Design and parameter optimization of rice pneumatic seeding metering device with adjustable seeding rate. Transactions of the CSAE, 2019; 35(4): 20-28. (in Chinese)

[21] Tian L Q, Tang H, Wang J W, Li S W, Zhou W Q, Yan D W. Design and experiment of rebound dipper hill-drop precision direct seed-metering device for rice. Transactions of the CSAM, 2017; 48(4): 65-72. (in Chinese)
[22] Tasaka K, Yoshinaga S, Matsushima K, Wakimoto K. Studies on the improvement of the hill seeding shape of shooting hill-seeder of rice combined with a paddy harrow. Journal of the Japanese Society of Agricultural Machinery, 2010; 65(1): 167-176.

[23] Long J R, Song C F, Ma G H, Tang H T, Zeng S, Luo X W, et al. Effects of mechanized precise hill-seeding and localized fertilization on rice growth and nutrient translocation. Hybrid Rice, 2014; 29(3): 60-64, 69. (in Chinese)

[24] Yamauchi M. A review of iron-coating technology to stabilize rice direct seeding onto puddled soil. Agronomy Journal, 2017; 109(3): 739-750.

[25] Wang J W, Li S W, Zhang Z, Li Q C. Design and experiment of electrical drive side deep hill-drop fertilization system for precision rice hill-direct-seeding machine. Transactions of the CSAE, 2018; 34(8): 43-54. (in Chinese)

[26] Xing H, Wang Z M, Luo X W, Zang Y, Zhang M H, Yang W W. Experimental study on relationship of seeding precision and germination rate in field of pneumatic rice hill-drop drilling planter. Transactions of the CSAE, 2018; 34(9): 42-48. (in Chinese)

[27] Wang W Q, Sardans J, Wang C, Pan T, Zeng C S, Lai D Y F, et al. Straw application strategy to optimize nutrient release in a southeastern China rice cropland. Agronomy, 2017; 7(4): 84.

[28] Zhang G Z, Zang Y, Luo X W, Wang Z M, Zeng S, Zhou Z Y. Design and experiment of oriented seed churning device on pneumatic seed metering device for rice. Transactions of the CSAE, 2013; 29(12): 1-8. (in Chinese)

[29] Anjum S A , Tanveer M , Carrijo D ,Akbar N. Comparative efficacy of various weed control measures in weed dynamics, yield and profitability of direct seeded fine rice. Pakistan Journal of Agricultural Sciences, 2017; 54(1): 129-134.

[30] Xing H, Zhang G Z, Han Y H, Gao Y, Zha X T. Development and experiment of double cavity pneumatic rice precision direct seeder. Transactions of the CSAE, 2020; 36(24): 29-37. (in Chinese)

[31] Zhang X J, Lai Y C, Meng Y, Zhang F M, Tang A, Dong W J, et al. Effects of planting patterns on growth, yield and temperature utilization of japonica rice in cold region. Crops, 2017; (5): 124-128. (in Chinese)

[32] Zhang H, Yu C, Chen K W, Kong X S, Liu H L, Chen J Y, et al. Effect of direct-seeding methods on physiological characteristics and grain yield of rice and its cost analysis. Transactions of the CSAE, 2017; 33(13): 58-64. (in Chinese)

[33] Greveniotis V, Zotis S, Sioki E, Ipsilandis C. Field population density effects on field yield and morphological characteristics of maize. Agriculture, 2019; 9(7): 160.

[34] Sudhir-Yadav, Humphreys E, Kukal S S, Gill G, Rangarajan R. Effect of water management on dry seeded and puddled transplanted rice Part 2: Water balance and water productivity. Field Crops Research, 2011; 120(1): 123-132.

[35] Sun Y J, Zhen H Z, Yang Z Y, Wang H Y, Zhang S W, Ma J. Effects of mechanical dry direct-sowing modes on absorption, translocation and distribution of nitrogen, phosphorus and potassium in rice. Transactions of the CSAE, 2017; 33(3): 73-80. (in Chinese) 